\title{
DESIGUALDADES NO MERCADO DE TRABALHO: ANÁLISE DA INDÚSTRIA PARANAENSE POR INTENSIDADE TECNOLÓGICA
}

\section{Andréia Ferreira Prestes' \\ Fernanda Mendes Bezerra ${ }^{2}$ \\ Lirane Elize Defante Ferreto ${ }^{3}$}

Resumo: O objetivo deste artigo é compreender o mercado de trabalho paranaense na perspectiva da indústria de transformação por intensidade tecnológica, nos anos de 2006 e 2015, com o intuito de inferir se existem diferenças entre homens e mulheres na participação, no rendimento, na escolaridade e no tempo de vínculo empregatício, nos segmentos modernos e tradicionais. Para isso, a metodologia utilizada foi análise descritiva dos dados extraídos do Ministério do Trabalho. Os resultados evidenciaram a preferência pela mão de obra masculina, uma vez que existe concentração e remuneração superior para os dois segmentos, apesar de as mulheres possuírem maior escolaridade.

Palavras-chave: Diferença entre gêneros; indústria de transformação; intensidade tecnológica.

Abstract: This article analyzes the labor market from the perspective of the industry being transformed by technology between 2006 and 2015 in Paraná. We verify if there are differences in the labor participation between men and women in income, education, and contract duration, including both modern and traditional segments. The methodology used was descriptive analysis of data obtained from the Brazilian Ministry of Labor. The results showed preference for male labor, given the presence of both higher concentration and salaries in the segments analyzed, despite women having higher education.

Keywords: Difference between genders; transformation industry; technological intensity.

\footnotetext{
1 Mestre em Gestão e Desenvolvimento Regional, Universidade Estadual do Oeste do Paraná, Brasil. E-mail: andreiafprestes@hotmail.com. Orcid: 0000-0002-3906-5608

2 Doutora em Economia, Universidade Estadual do Oeste do Paraná, Brasil. E-mail: ferpompeia@gmail.com. Orcid: 0000-0002-3307-0107

3 Doutora em Saúde Coletiva, Universidade Estadual do Oeste do Paraná, Brasil. E-mail: Iferreto@hotmail.com. Orcid: 0000-0002-0757-3659
} 


\section{Introdução}

mercado de trabalho é um tema de grande relevância, uma vez que expressa a situação econômica de uma região por meio da geração de renda, a qual deve compreender uma distribuição uniforme, o que, caso contrário, pode acarretar desigualdade social. Em vista disso, pesquisas com diversos focos buscam compreender o mercado de trabalho. Segundo Lima (1980), uma das teorias bastante utilizadas para essa explicação é a do capital humano, que sofreu críticas ao generalizar que o aumento da remuneração acompanha o aumento da escolaridade.

A partir de então, surgiu a teoria da segmentação do mercado de trabaIho (TSMT), que busca novas alternativas para explicar esse mercado, com a separação da estrutura produtiva em setores a fim de verificar se existe discriminação dentro desses segmentos. A TSMT defende que em setores intensivos em tecnologia os trabalhadores são mais qualificados e recebem maior remuneração, sendo chamados de segmento primário ou moderno. Já nos setores mais intensivos em mão de obra os trabalhadores possuem menor nivel de escolaridade e baixa remuneração, sendo estes chamados de segmento secundário ou tradicional (SILVA, 2006).

De acordo com a Relação Anual de Informações Sociais (RAIS), um dos setores que combina ambos os segmentos, além de contribuir com 31,32\% dos empregos formais no estado do Paraná no ano de 2015, é a indústria de transformação (IT) (BRASIL, 2017). De acordo com o Instituto Brasileiro de Geografia e Estatística (IBGE, 2017), esse setor é composto por 24 atividades com características distintas na estrutura produtiva. Em vista disso, esse ramo será desagregado nos dois segmentos já mencionados, em que o moderno é composto pelos setores cuja intensidade tecnológica se caracteriza como de média-alta e alta intensidade, e o tradicional pelos de baixa e média-baixa tecnologia.

Esses segmentos são compostos por cadeias de produção diferentes, nas quais variam desde as condições de trabalho até a remuneração final. Ometto (1997) afirma que a distribuição dos trabalhadores não ocorre de forma homogênea dentro do mercado de trabalho, havendo desigualdade entre os sexos ${ }^{4}$. Para a autora, as mulheres encontram barreiras no acesso

4 ○ termo "sexo" trata das questões biológicas, isto é, referentes a alguns elementos corporais, como genitálias, aparelhos reprodutivos, seios etc. Por sua vez, o gênero é uma distinção social dos sexos, de maneira que homens e mulheres são produto do contexto social e histórico, e não resultado da anatomia de seus corpos (ARAÚJO, 2005). 
aos cargos de maior prestígio e, por esse motivo, se concentram nas funções menos valorizadas e com remunerações desiguais, se comparadas com as dos homens.

Em vista disso, a fim de compreender o mercado de trabalho paranaense, esta pesquisa visa analisar, com base na TSMT, os dois segmentos da IT com o propósito de investigar se existe desigualdade entre homens e mulheres na participação, na remuneração, na escolaridade e no tempo de vínculo empregatício, nos anos de 2006 e 2015, por meio da análise descritiva dos dados da RAIS.

\section{Teoria da segmentação do mercado de trabalho: aspectos teóricos e empíricos}

Na transição das décadas de 1960 a 1970, a teoria do capital humano foi alvo de críticas por afirmar que níveis mais altos de educação correspondem a maior rendimento. $\bigcirc$ contraponto a essa teoria é que esta não analisa que as diferenças salariais advêm de diversas estruturas; portanto, não se pode afirmar que a renda cresce juntamente com a educação em mercados distintos (LIMA, 1980).

Para Silva (2006), a inadequação da teoria do capital humano deu origem a uma nova tese, chamada de TSMT ou "mercado dual". Esse conceito ganhou relevância pelo aprimoramento da análise e por estipular uma nova alternativa de explicação dos níveis salariais e da mobilidade ocupacional. A TSMT não se preocupa em observar apenas o mercado de trabalho como um todo, mas também o funcionamento do local exato em que a renda dos trabalhadores é gerada, e explicaria o papel da educação como determinante da distribuição de renda. Contudo, essa teoria se sobressai diante da alocação de trabalhadores em diferentes segmentos de trabalho, isto é, quando os indivíduos com diferentes níveis escolares estão propensos à distinção no acesso ao mercado de trabalho. Portanto, o papel da educação, no modelo dual, é dar as condições para o acesso dos trabalhadores a certos segmentos. Segundo Macedo (1982), a educação formal atua como um critério para selecionar ou distribuir os diversos ramos do mercado de trabalho entre os interessados.

Segundo Lima (1980), os autores que colaboraram para desenvolver a TSMT foram Doeringer e Piore (1971). Uma das contribuições dos autores se refere à divisão do mercado de trabalho por segmentos, primário e 
secundário, os quais se caracterizam pelo ramo de atividade e se diferenciam de acordo com a estabilidade empregatícia. Para Souza (1978), essa diferenciação está atrelada ao resultado da crescente especificidade das funções, advinda da qualificação exigida para seu desempenho.

No mercado primário encontram-se os trabalhadores que possuem um emprego estável, em que as habilidades são adquiridas dentro da própria empresa, a remuneração é mais elevada e as chances de subir de cargo são maiores (REICH; GORDON; EDWARDS, 1973). Para Calabi e Zaghen (1976), além dessas qualidades, esse segmento apresenta um maior progresso técnico, o que acarreta um aumento de produtividade. $\bigcirc$ segmento primário é denominado como "setor moderno" na economia - isto porque se associa a um processo tecnologicamente mais desenvolvido.

Para Souza (1978), esse mercado atende à necessidade do empregador quanto à aplicação de recursos para o treinamento e implica a minimização da rotatividade, além de satisfazer os próprios trabalhadores pela estabilidade e pelas vantagens referentes às habilidades e aos conhecimentos adquiridos, além da probabilidade de promoção.

Já no segmento secundário, os trabalhadores possuem menos estabilidade, não recebem qualificação dentro da empresa, os salários são mais baixos e as chances de promoção são mínimas (REICH; GORDON; EDWARDS, 1973). Para Souza (1978), nesse mercado, os empregadores não investem em treinamento para seus colaboradores. Segundo Lima (1980), o segmento secundário apresenta alta rotatividade de funcionários, por motivos já citados, além de más condições de trabalho, baixo nível tecnológico e de produtividade, e maior número de desempregados. Como no segmento secundário os processos produtivos apresentam menor nível tecnológico, ele é chamado, na economia, de "setor tradicional".

$\mathrm{Na}$ busca pela identificação das causas da segmentação dual do mercado, três correntes teóricas se complementam. A literatura considera como sustentação teórica da TSMT as contribuições dos autores: Doeringer e Piore (1971), Vietorisz e Harrison (1973), Bluestone (1970) e, por fim, Reich, Gordon e Edwards (1973).

Doeringer e Piore, em 1971, defenderam que as características de cada trabalhador (raça, sexo, escolaridade, experiência, entre outras) são consideradas fator determinante do tipo de mercado em que será alocado, além de considerarem o treinamento como primordial para elevação da renda. De acordo com Souza (1978), para Doeringer e Piore a alocação inicial no 
mercado de trabalho instável irá determinar as futuras inserções do indivíduo, além de influenciar as decisões dos próprios filhos. A discriminação social também está presente no estudo de Doeringer e Piore, analisando-a mais como fator cultural advindo da evolução histórica do sistema capitalista e do processo de divisão do trabalho (SOUZA, 1978).

Bluestone (1970) e Vietorisz e Harrison (1973) apresentam um enfoque diferente quando buscam analisar o comportamento da estrutura industrial com base no perfil dos trabalhadores das empresas e suas relações (LIMA, 1980). Para Souza (1978), os autores defendem que a composição do segmento primário e secundário do mercado de trabalho se origina nas diferenças tecnológicas industriais. Os mesmos autores defendem que esse dualismo é proveniente do próprio sistema capitalista, no qual os altos salários do mercado primário incentivam a adoção de técnicas inovadoras intensivas em capital, pois o capital humano acompanha o capital físico, o que resulta no aumento da produtividade devido à qualificação dos funcionários (SOUZA, 1978).

Ainda nessa perspectiva, Bluestone (1970) e Vietorisz e Harrison (1973) afirmam que, no mercado secundário, utiliza-se de técnicas intensivas em mão de obra e inexiste investimento em capital humano, mantendo os salários e a produtividade estagnados. Portanto, os autores admitem que o mercado de trabalho funciona como um mecanismo em que o desenvolvimento diverge do ciclo técnico de produção, além de implicar a segmentação e a diferença de salários entre os ramos setoriais, explicando a desigualdade de classes sociais. Essas afirmações são norteadas pelas condições tecnológicas predominantes na economia (SOUZA, 1978).

Conforme Reich, Gordon e Edwards (1973), a segmentação do mercado de trabalho se originou de acordo com a evolução histórica, na transformação do capitalismo competitivo para o monopolista, isto é, as forças da economia corroboraram para a divisão em submercados (segmentos), distinguindo uns dos outros pelas características e regras do mercado de trabalho. De acordo com Silva (2006), Reich também responsabiliza o sistema educacional como fator de diferenciação dos segmentos e das classes sociais, sendo a ampliação do dualismo também vinculada com o preconceito de raça e sexo.

De acordo com Souza (1978), o mercado dual de trabalho é bisseccionado, dado que de um lado se encontram as grandes empresas oligopolistas, com empregos primários, e de outro lado as empresas competitivas, com 
empregos secundários, sendo que a principal diferença entre elas, além do nível tecnológico, é o grau de escolaridade e a remuneração.

De forma geral, as três abordagens teóricas defendem que a existência de um mercado de trabalho dual, por meio do segmento primário (moderno) e do secundário (tradicional), resulta na disparidade salarial não justificada pela capacidade produtiva, em que os trabalhadores mal remunerados não possuem as mesmas oportunidades de emprego que aqueles com melhor remuneração. Dessa forma, o empregador apresenta uma atitude irracional e discriminatória no momento de contratação, fortalecendo, assim, a persistente diferença nos rendimentos. Por conta disso, inúmeras pesquisas utilizam a TSMT em diversos segmentos trabalhistas.

Com o intuito de retratar a segmentação dos empregos padronizados e não padronizados na Alemanha, Garz (2013) utiliza dados do painel socioeconômico dos anos de 2001 a 2010. O autor identifica dois segmentos: na determinação de salários e nas características dos trabalhadores e do trabatho em si. Além de identificar a inferioridade dos salários do setor secundário perante o primário - em média 11,65 euros a menos por hora -, apenas $22 \%$ dos trabalhadores no setor secundário são homens. Outro fator diz respeito às barreiras da mobilidade de um segmento para outro.

Também utilizando a TMST, Alt e lversen (2017) combinam o modelo de preferências de segurança para a redistribuição de renda. Concluíram que a segmentação do mercado de trabalho tem mais efeitos consistentes do que a distância social entre os pobres e a classe média. A redução do apoio para a redistribuição de renda, nas últimas três décadas, teve maior participação no aumento da segmentação do que influência na elevação da heterogeneidade étnica e social da distância entre as classes médias e pobres.

Ao buscar analisar o mercado de trabalho da China com base na evolução salarial, para os anos de 1988, 1995, 2002 e 2007, Wang, Piesse e Ye (2016) investigaram por meio da aplicação do modelo de lucro de Mincer. Para os autores, o aumento da desigualdade está relacionado a dois fatores: a diferença de renda e a disparidade interprovíncia entre os segmentos urbano e rural. Os resultados demonstram a existência de níveis regionais diferentes, mas também uma segmentação setorial, em que as atividades rurais acabam sofrendo mais. Retratam, também, que pessoas de diferentes setores não recebem de acordo com a sua produtividade.

Apresentando uma visão diferente de Wang, Piesse e Ye (2016), Rubery e Piasna (2016), ao fazer uma análise descritiva da TSMT para 
o ano de 2014, com base na agenda de reformas de mercado da União Europeia, relatam que o mercado de trabalho oferece inúmeras oportunidades, que abrangem vários termos e condições de laboração, em que a produtividade/potencial inata dos trabalhadores não tem influência. Entretanto, afirmam que os trabalhos são estratificados por fatores como: "classes sociais, acesso à educação, responsabilidades familiares, restrições geográficas, idade e vulnerabilidade à discriminação" (RUBERY; PIASNA, 2016, p. 25). Segundo essas autoras, as politicas sociais e as organizações sindicais são capazes de minimizar essa situação, proporcionando melhores condições de trabalho. No entanto, haveria a necessidade de mecanismos para nivelar o emprego e proteger a classe menos favorecida, garantindo trabalho justo e estabilidade na renda.

Atitudes discriminatórias no mercado de trabalho, envolvendo questões relacionadas a raça, sexo, grupos demográficos da população, entre outras, proporcionam uma maior disparidade nos rendimentos e, assim, maior desigualdade social. Em vista disso, a próxima seção busca trazer as principais contribuições teóricas e empíricas voltadas para a segmentação e para a diferença salarial entre homens e mulheres.

\section{Desigualdade entre o sexo feminino e o masculino: aspectos teóricos e empíricos}

A desigualdade no mercado de trabalho pode ser detectada, principalmente, quanto à sua divisão sexual em segmentos. De acordo com Ometto (1997), a distribuição dos trabalhadores não ocorre de forma igualitária no mercado de trabalho. Para ela, as mulheres encontram barreiras no acesso aos cargos de maior prestígio e, por esse motivo, se concentram nas funções menos valorizadas. Em vista disso, inúmeras pesquisas se voltaram para o estudo da desigualdade entre homens e mulheres no mercado trabalhista.

Conforme apontam Cugini et al. (2014), a desigualdade entre homens e mulheres está inserida na sociedade há séculos, uma vez que o homem era responsável pelo sustento da casa, e a mulher apenas pelos afazeres domésticos. No entanto, a participação feminina no mercado de trabalho vem apresentando aumento. Segundo Baylão e Schettino (2014), essa inclusão está atrelada à necessidade de aumentar a renda familiar. Para Silva (2014), a incorporação feminina no ramo trabalhista brasileiro está ocorrendo em diversos setores, resultado do aumento da escolaridade, da redução da fecundidade e da industrialização do país. 
Com o intuito de verificar a desvalorização do sexo feminino na Suécia nos anos de 2001 e 2003, Magnusson (2013) utilizou a análise funcional, transversalmente e em painel. O resultado da pesquisa indica que a proporção de mulheres está negativamente relacionada com os salários recebidos, o que é interpretado pela autora como desvalorização do trabalho voltado para essa classe.

Abendroth, Maas e Lippe (2013) investigam a ocupação por mulheres de cargos de autoridade política em países europeus, nos anos 2004 e 2005. As autoras evidenciaram que a experiência de trabalho global, bem como o empregador atual e as horas trabalhadas, corroboram para a explicação da diferença entre homens e mulheres em cargos de autoridade. Outros fatores que têm influência, porém com menos intensidade, são a especialização educacional e interrupções de carreira. Para as autoras, o capital humano, em diferentes países da Europa, não explica essas lacunas, embora tenha sido possivel identificar diferenças salariais entre ocupantes de cargos de autoridade política.

Com o objetivo de explicar diferenças salariais entre recém-formados, Triventi (2013) examinou 11 países da Europa. Os resultados das regressões mostraram que em todos os paises existem diferenças salariais significativas, e que a discriminação é menor em países nórdicos e maior na República Tcheca, no Reino Unido e no sul da Europa. $O$ autor conclui que a diferença de gênero está associada a fatores voltados para a particularidade de cada emprego e a carga horária, de forma que a discriminação é menor nos países com forte participação sindical e políticas adequadas para a família, promovendo maior participação da mulher na sociedade.

$\mathrm{Na}$ busca por explicações das lacunas existentes em segmentos trabalhistas quando o assunto envolve as diferenças que afetam homens e mulheres no contexto do trabalho, Peetz (2015) analisa a regulação e a distância da regulação. Segundo o autor, uma maior dependência do mercado acarreta diferenças salariais, ainda mais quando se trata de sexos opostos. Analisando os trabalhos de diversos países, em especial da Austrália, o autor retrata algumas implicações políticas em relação à equidade entre homens e mulheres, tais como quebra de barreiras do mercado trabalhista e regulamentação do salário da mulher a fim de diminuir a discriminação e garantir uma carreira igualitária, com perspectiva de crescimento profissional.

No âmbito nacional, Moraes (2005) analisa a diferença salarial na IT brasileira para os anos de 1993, 1998 e 2003. A autora evidencia que 
as mulheres são mais escolarizadas que os homens; no entanto, mantêm menor tempo de vínculo com as empresas. As mulheres atuam principalmente no segmento tradicional, nos setores de vestuário, indústria alimentícia, têxtil e calçadista. Além disso, na maior parte dos setores, o salário das mulheres é inferior ao dos homens, de forma que grande parte dessa diferença se caracteriza como discriminação, conforme mostra o método de Horrace e Oaxaca (2001 apud MORAES, 2005).

Devido às mudanças sociais na estrutura familiar e na ocupação da mulher, Guedes e Araújo (2011) fizeram um diagnóstico socioeconômico mediante a menção de políticas de igualdade entre os sexos. As autoras evidenciaram a inserção da mão de obra feminina no mercado de trabalho e a maior escolaridade; porém, também verificaram a permanência da diferença salarial, principalmente nos grupos com alta escolaridade, e a segmentação em funções de menor prestígio, com baixa remuneração. Com isso, as autoras concluíram que a igualdade ainda está distante da realidade.

Camargos, Riani e Marinho (2014) analisaram as relações entre os gêneros no mercado de trabalho mineiro. Verificaram que a desigualdade entre homens e mulheres se origina de alguns fatores como: o ingresso no mercado de trabalho, a participação dentro dos segmentos, o rendimento e o tempo despendido entre trabalho produtivo e reprodutivo.

Para a região Sul do Brasil, especialmente para o estado do Paraná, FiuzaMoura et al. (2014) identificaram uma probabilidade de segmentação e discriminação sexual por intensidade tecnológica na IT, com diferenças salariais entre os segmentos, baixa participação e remuneração feminina, além de barreiras de entrada no mercado de trabalho para as mulheres menos escolarizadas.

De acordo com a contribuição da literatura, percebe-se que a desigualdade sexual está presente em vários segmentos no mercado de trabalho. Nessa perspectiva de problematização das relações sociais, esta pesquisa visa analisar dois segmentos com características diferentes da IT, corroborando os estudos já existentes, na busca pelo entendimento das diferenças entre os homens e as mulheres no mercado de trabalho.

\section{Procedimentos metodológicos}

Esta seção tem como propósito fazer uma apresentação do período a ser analisado; dos setores da IT, separando-os, de acordo com a intensidade tecnológica, em segmento tradicional e moderno; além de abordar as fontes de dados do estudo. 


\section{Dados da pesquisa}

Este trabalho tem como base os anos de 2006 e 2015, os quais foram escolhidos pela disponibilidade de dados em comum, juntamente com as oscilações da economia brasileira. Conforme Paula e Pires (2017), o período de 2004 a 2013 foi marcado por um crescimento médio de 4\% ao ano e pela melhoria na distribuição de renda e pobreza. No entanto, entre 2015 e 2016, o cenário se altera e o país passa por uma recessão, resultando em queda de 3,7\% do produto interno bruto (PIB) e piora dos indicadores sociais. Além disso, conforme os autores, entre 2010 e 2014 a economia internacional enfrentava a crise do Euro, a fraca recuperação norte-americana e a desaceleração do crescimento mundial, que passou de $5,1 \%$, em 2010, para 3,1\% em 2014. Tais fatores geraram consequências negativas para a economia brasileira, as quais foram minimizadas com políticas intervencionistas.

Com as oscilações ocorridas na economia, um dos segmentos que mais sentiu reflexos foi o mercado de trabalho. Dessa maneira, com o auxílio da estatística descritiva, serão analisados os dados de emprego na IT do estado do Paraná, por meio da observação anual e por segmento, nas seguintes variáveis: distribuição no mercado de trabalho entre homens e mulheres; remuneração média; tempo médio de permanência na empresa; e período médio de estudo e escolaridade, separada em cinco níveis (analfabeto, $5^{\circ}$ ano completo do ensino fundamental, ensino fundamental completo, ensino médio completo e ensino superior completo). Os dados utilizados referem-se aos microdados da RAIS, que era desenvolvida pelo então Ministério do Trabalho e Emprego (MTE) e consiste no principal banco de dados voltado para o mercado de trabalho brasileiro.

A ordenação dos dados teve como base as informações do IBGE (2017), de acordo com a Comissão Nacional de Classificação (Concla), a partir da divisão da Classificação Nacional de Atividades Econômicas (CNAE 2.0), seção C, que representa os 24 setores da IT. Todos os setores que compõem a IT foram separados em dois segmentos, de acordo com a intensidade tecnológica de cada ramo: o segmento primário, conhecido como moderno, abrange os setores que utilizam alta e média-alta tecnologia; e o secundário, representado pelo setor tradicional, é composto pelos segmentos com baixa e média-baixa intensidade tecnológica. Tal divisão se embasou nas informações do IBGE (2017), por meio da Pesquisa Industrial Anual (PIA), elencadas na Tabela 1. 
Tabela 1: Setores da indústria de transformação por intensidade tecnológica

\begin{tabular}{|c|c|c|}
\hline Setor - CNAE 2.0 & $\begin{array}{l}\text { Intensidade } \\
\text { tecnológica }\end{array}$ & Segmento \\
\hline 10 - Fabricação de produtos alimentícios & Baixa & \multirow{13}{*}{ 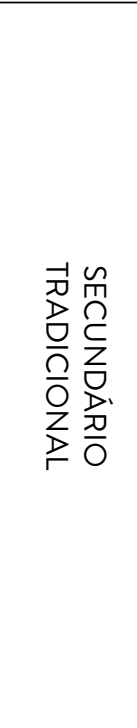 } \\
\hline 11 - Fabricação de bebidas & Baixa & \\
\hline 13 - Fabricação de produtos têxteis & Baixa & \\
\hline 14 - Confecção de artigos do vestuário e acessórios & Baixa & \\
\hline $\begin{array}{l}15 \text { - Preparação e fabricação de artefatos de couro, } \\
\text { artigos para viagem e calçados }\end{array}$ & Média-baixa & \\
\hline 16 - Fabricação de produtos de madeira & Baixa & \\
\hline 18 - Impressão e reprodução de gravações & Baixa & \\
\hline $\begin{array}{l}19 \text { - Fabricação de coque, de produtos derivados do } \\
\text { petróleo e de biocombustíveis }\end{array}$ & Baixa & \\
\hline $\begin{array}{l}22 \text { - Fabricação de produtos de borracha e de material } \\
\text { plástico }\end{array}$ & Média-baixa & \\
\hline 23 - Fabricação de produtos de minerais não metálicos & Média-baixa & \\
\hline 24 - Metalurgia & Média-baixa & \\
\hline $\begin{array}{l}25 \text { - Fabricação de produtos de metal, exceto máquinas e } \\
\text { equipamentos }\end{array}$ & Média-baixa & \\
\hline 31 - Fabricação de móveis & Baixa & \\
\hline 12 - Fabricação de produtos do fumo & Média-alta & \multirow{11}{*}{ 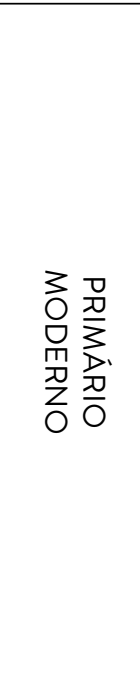 } \\
\hline 17 - Fabricação de celulose, papel e produtos de papel & Média-alta & \\
\hline 20 - Fabricação de produtos químicos & Média-alta & \\
\hline $\begin{array}{l}21 \text { - Fabricação de produtos farmoquímicos e } \\
\text { farmacêuticos }\end{array}$ & Média-alta & \\
\hline $\begin{array}{l}26 \text { - Fabricação de equipamentos de informática, } \\
\text { produtos eletrônicos e ópticos }\end{array}$ & Alta & \\
\hline $\begin{array}{l}27 \text { - Fabricação de máquinas, aparelhos e } \\
\text { materiais elétricos }\end{array}$ & Alta & \\
\hline 28 - Fabricação de máquinas e equipamentos & Alta & \\
\hline $\begin{array}{l}29 \text { - Fabricação de veículos automotores, } \\
\text { reboques e carrocerias }\end{array}$ & Alta & \\
\hline $\begin{array}{l}30 \text { - Fabricação de outros equipamentos de transporte, } \\
\text { exceto veículos automotores }\end{array}$ & Alta & \\
\hline 32 - Fabricação de produtos diversos & Média-alta & \\
\hline $\begin{array}{l}33 \text { - Manutenção, reparação e instalação de } \\
\text { máquinas e equipamentos }\end{array}$ & Alta & \\
\hline
\end{tabular}

Fonte: Elaboração própria com base no IBGE (2017).

\section{Resultados e discussões}

Os resultados desta pesquisa se encontram divididos em duas partes: a primeira faz uma abordagem da distribuição do emprego, e a segunda analisa os rendimentos, a escolaridade e o tempo médio de empresa dentro dos segmentos. 


\section{Distribuição do emprego por segmento}

O estado do Paraná apresentou um aumento expressivo no total de empregos formais, que passou de 2.251.290, em 2006, para 3.113.204, em 2015. Dos trabalhadores do ano de 2006, 58,05\% eram homens e $41,94 \%$ mulheres; entretanto, no ano de 2015 , os do sexo masculino passaram para $55 \%$, e do feminino para $45 \%$. Percebe-se que, apesar de o sexo feminino apresentar desvantagem perante o masculino, essa diferença tem diminuído com o passar dos anos. Conforme Itaboraí (2016), o crescimento da participação feminina no mercado de trabalho está relacionado com o aumento da escolaridade das mulheres e com a transformação de suas identidades.

Com o passar dos anos, a mulher vem adquirindo maior independência financeira e melhor posição na sociedade. De acordo com Cugini et al. (2014), essa evolução está atrelada à necessidade de aumento da renda domiciliar e, como aponta Silva (2014), à industrialização brasileira dos anos 1970, fatores que contribuíram também para a elevação do nível de escolaridade da mulher e a redução da fecundidade, proporcionando maiores oportunidades no mercado de trabalho nos anos subsequentes.

Além dos fatores mencionados pelos autores, outro motivo que contribuiu para o aumento da participação feminina no mercado de trabalho foi a criação da Secretaria Especial de Políticas para as Mulheres da Presidência da República, em 2003, e a realização da I Conferência Nacional de Políticas para as Mulheres, em 2004, na qual foram apresentadas propostas para a elaboração do Plano Nacional de Políticas para as Mulheres. $\bigcirc$ Plano consiste em ações para superar as desigualdades entre homens e mulheres no Brasil, além de reconhecer o papel do Estado por meio de ações e políticas de combate à desigualdade social (BRASIL, 2005).

Do total de empregos já citado, a IT apresenta uma participação representativa para o mercado de trabalho paranaense, equivalente a $33,77 \%$ no ano de 2006 , e a $31,32 \%$ em 2015. Apesar da queda percentual em relação aos outros setores, a IT gerou 214.893 empregos no período de 2006 a 2015 (BRASIL, 2017). Para melhor análise, esse setor é separado por intensidade tecnológica e por sexo, conforme mostra a Tabela 2 . 
Tabela 2: Total de empregos na indústria de transformação por setor e por sexo

\begin{tabular}{lcccccc}
\hline \multirow{2}{*}{ Setor } & \multicolumn{2}{c}{ Total amostra } & \multicolumn{2}{c}{ Masculino } & \multicolumn{2}{c}{ Feminino } \\
\cline { 2 - 7 } & $\mathbf{2 0 0 6}$ & $\mathbf{2 0 1 5}$ & $\mathbf{2 0 0 6}$ & $\mathbf{2 0 1 5}$ & $\mathbf{2 0 0 6}$ & $\mathbf{2 0 1 5}$ \\
\hline Tradicional & 586.993 & 723.578 & 397.510 & 453.205 & 189.483 & 270.373 \\
Moderno & 173.300 & 251.608 & 138.442 & 190.655 & 34.858 & 60.953 \\
Total & 760.293 & 975.186 & 535.952 & 643.860 & 224.341 & 331.326 \\
\hline
\end{tabular}

Fonte: Elaboração própria com base nos dados do MTE (BRASIL, 2017).

Observa-se, na Tabela 2, que no ano de 2006 o setor tradicional representou uma participação de $77,2 \%$ do total de empregos, e o moderno de $22,8 \%$. No ano de 2015 , essa porcentagem passou para $74,2 \%$ e $25,8 \%$, respectivamente. Apesar do pequeno ajuste, seu impacto no mercado de trabalho paranaense é expressivo, pois como o setor tradicional é mais intensivo em mão de obra e utiliza baixos fatores tecnológicos, isso significa que o número de empregos é maior, embora com menor qualidade.

De acordo com Moraes (2005), se comparado com a indústria tradicional, o aumento da participação do segmento moderno faz com que a geração de emprego seja menor, pois concentra menor participação de trabalhadores, de forma que a sua necessidade seja compensada pela utilização de tecnologias. Entretanto, conforme aponta Silva (2006), o segmento moderno exige maior qualificação e resulta em uma remuneração superior, de forma a impactar positivamente a geração de renda no funcionamento da economia.

Segundo Moraes (2005), no Brasil, a IT concentra a maior parte dos trabalhadores no segmento tradicional, justamente por ser mais intensivo em mão de obra. No entanto, para a autora, a concentração é maior para o sexo feminino, enquanto os homens se distribuem entre ambos os segmentos de forma mais equilibrada.

A Tabela 2 também mostra a participação por sexo dentro dos dois segmentos. Nota-se que no tradicional, no ano de 2006, os homens tinham $68 \%$ de participação, e as mulheres apenas $32 \%$. No ano de 2015 , a participação do sexo masculino diminuiu para $62,63 \%$, e a do feminino aumentou para $37,37 \%$. No setor moderno, a atuação dos homens é ainda maior, representando $80 \%$ do total no ano de 2006 , e $75,77 \%$ em 2015 . A variação de cada sexo no período analisado foi um aumento de $83,24 \%$ para os homens, e de $67,71 \%$ para as mulheres.

Percebe-se que tanto $o$ ingresso das mulheres quanto a sua atuação no mercado de trabalho são inferiores se comparados com os dos homens em ambos os segmentos nesse período. De acordo com Baylão e 
Schettino (2014), apesar do progresso do sexo feminino no mercado de trabalho, as mulheres ainda apresentam menor participação, possuem cargos inferiores e enfrentam barreiras de oportunidades, tanto na inserção no mercado de trabalho como na evolução para cargos de maior prestígio e, principalmente, em relação à desigualdade salarial.

Dos setores que compõem o segmento tradicional, no ano de 2006, se destaca como maior gerador de empregos a fabricação de produtos alimentícios, com 32,88\% de participação, seguida da confecção de artigos de vestuário e acessórios, com 15\%. No ano de 2015, o cenário não foi diferente: os mesmos setores apresentaram participação de 40,27\% e $12,70 \%$, respectivamente.

Por outro lado, no segmento moderno, os setores com maior destaque de emprego são: fabricação de veículos automotores, reboques e carrocerias, representando 25,67\% em 2006 e 21,36\% em 2015; seguido do setor de fabricação de máquinas e equipamentos, que passou de $15,57 \%$ para 19,13\%; e fabricação de celulose, papel e produtos de papel, que passou de $14,75 \%$ para $12,93 \%$.

Ao detalhar cada segmento, percebe-se que no ramo tradicional, no ano de 2006, a participação masculina estava concentrada, com 47\%, em apenas dois setores: fabricação de produtos alimentícios e de madeira. No entanto, no ano de 2015, houve uma desconcentração e os homens passaram a atuar, para além dos dois setores já citados, em mais dois: fabricação de produtos de metal e de móveis, totalizando um percentual de $67,76 \%$ de participação nos quatro setores.

No que tange ao segmento moderno, no ano de 2006, o sexo masculino estava presente principalmente na fabricação de máquinas e equipamentos e na fabricação de veículos automotores, reboques e carrocerias, com um total de 45\%. No ano de 2015 não houve grandes alterações, pois a atuação no segmento moderno permaneceu a mesma e o percentual se alterou minimamente para $44,57 \%$. Essa estabilidade ocorre por serem áreas que exigem características mais masculinas do que femininas.

Quanto ao sexo feminino, no ano de 2006, no segmento tradicional, 67,31\% concentravam-se na fabricação de produtos alimentícios e na confecção de artigos de vestuário e acessórios. No segmento moderno há uma maior dispersão do trabalho feminino entre os setores, entretanto os principais são a fabricação de produtos químicos 
e a fabricação de produtos diversos, com participação de $28,95 \%$. No ano de 2015, o segmento tradicional permanece com a maior participação dos setores já citados, aumentando, entretanto, para 69,13\%. No mesmo ano, porém no setor moderno, o sexo feminino passa a atuar, além dos setores já citados no ano de 2006, no setor de fabricação de veículos automotores, reboques e carrocerias (16,07\%), totalizando $42,70 \%$ nos três setores.

Cabe destacar que o setor de fabricação de veículos automotores, reboques e carrocerias é uma área tipicamente masculina. Dessa maneira, é possivel visualizar que as mulheres estão ganhando participação em setores que antes eram predominantemente masculinos. Conforme Baylão e Schettino (2014), para além do setor industrial, a presença da mão de obra feminina está ganhando espaço na agropecuária e no comércio, com aumento percentual de $8 \%$ e $6 \%$, respectivamente.

Como se pode perceber, apesar de os homens serem maioria nos dois segmentos, nota-se também que, com o passar do tempo, a participação de mulheres no mercado de trabalho está diversificando a sua atuação em setores que anteriormente eram voltados para os homens. A demonstração analítica desses dados põe em evidência certa evolução da atuação da mulher na sociedade, tal como sua posição e independência financeira.

\section{Análise da remuneração, da escolaridade e do tempo médio de empresa nos segmentos}

Com base nos dados, percebe-se que os trabalhadores da IT, tanto no segmento moderno como no tradicional, não apresentam a mesma jornada de trabalho. Em vista desse contexto, fez-se necessário estimar os salários com base nas horas trabalhadas para, posteriormente, verificar se existe diferença nos rendimentos entre os setores e entre os gêneros.

Após tais ajustes, os rendimentos por hora trabalhada foram calculados e dispostos na Tabela 3. O salário médio masculino é representado por $\bar{Y} m$, a média do salário feminino por $\bar{Y} f$, e o desvio-padrão para ambos os casos é expresso por $d p$. Por conseguinte, a diferença salarial entre os sexos é expressa por $\bar{Y} f-\bar{Y} m$ - quando o resultado dessa equação apresenta sinal negativo, significa que a remuneração das mulheres é menor que a dos homens; se o sinal for positivo, as mulheres são mais bem remuneradas. 
Tabela 3: Média salarial por hora de trabalho (R\$)

\begin{tabular}{cccccccccccc}
\hline \multirow{3}{*}{ Setor } & \multicolumn{4}{c}{2006} & \multicolumn{4}{c}{$\mathbf{2 0 1 5}$} & $\mathbf{2 0 0 6}$ & $\mathbf{2 0 1 5}$ \\
\cline { 2 - 13 } & \multicolumn{1}{c}{ Masculino } & Feminino & \multicolumn{2}{c}{ Masculino } & Feminino & Diferença & Diferença \\
\cline { 2 - 12 } & $\bar{Y} m$ & $d p$ & $\bar{Y} f$ & $d p$ & $\bar{Y} m$ & $d p$ & $\bar{Y} f$ & $d p$ & $\bar{Y} f-\bar{Y} m$ & $\bar{Y} f-\bar{Y} m$ \\
\hline Tradicional & 4,31 & 6,01 & 3 & 3,55 & 9,76 & 10,87 & 7,03 & 6,53 & $-1,31$ & $-2,73$ \\
Moderno & 8,15 & 11,71 & 5,72 & 7,97 & 15,72 & 19,37 & 11,27 & 13,83 & $-2,43$ & $-4,45$ \\
\hline
\end{tabular}

Fonte: Elaboração própria com base nos dados do MTE (BRASIL, 2017).

A análise dos salários por segmento comprova a afirmação feita pela literatura (CALABI; ZAGHEN, 1976; LIMA, 1980; REICH; GORDON; EDWARDS, 1973; SILVA, 2006; SOUZA, 1978) de que o moderno é mais bem remunerado que o tradicional, o que pode ser visualizado tanto em 2006 quanto em 2015. Percebe-se também que a diferença salarial, tanto por segmento como por sexo, vem aumentando no decorrer dos anos, demonstrando que o preconceito ainda está enraizado na sociedade, gerando dificuldade na integração e aceitação da mulher no mercado de trabalho.

desvio-padrão (dp), na maior parte dos casos, encontra-se acima da média, o que significa que há uma maior dispersão no salário dos trabalhadores. Essa maior distribuição está presente principalmente no segmento moderno para o sexo masculino, além de apresentar crescimento de um ano para o outro. Uma menor dispersão pode ser localizada no segmento tradicional para o sexo feminino, chegando a ficar abaixo da média no ano de 2015.

Quando a análise está voltada para a diferença salarial entre os sexos, é possível visualizar que, para ambos os anos e segmentos, o sexo feminino recebe remuneração inferior à do masculino. Essa diferença está aumentando com o passar dos anos, disparidade que se encontra principalmente no segmento moderno, chegando a $-4,45$ reais por hora no ano de 2015 . Segundo Fiuza-Moura et al. (2014), é possivel que haja um viés entre os salários do sexo masculino e feminino em setores com alto nível tecnológico por ser o posto de trabalho tipicamente masculino.

Magnusson (2013), ao analisar dados suecos, chegou a resultados semelhantes, em que os salários das mulheres são inferiores no mercado de trabalho. Para a autora, isso se caracteriza como desvalorização do trabalho feminino. As pesquisas de Moraes (2005), sobre o Brasil, e de Fiuza-Moura et al. (2014), sobre o Sul do país, evidenciam que grande parte dessa desigualdade se caracteriza como discriminação do sexo feminino dentro dos segmentos da IT. 
Por fim, os dados da Tabela 3 permitem inferir que, além de os homens receberem mais que as mulheres, principalmente no segmento moderno, o salário de alguns trabalhadores masculinos apresenta uma distância maior da média, indicando que existem alguns outliers no segmento, como demonstra o dp. Já para as mulheres, também são evidenciadas algumas diferenças, porém menores do que no sexo masculino. No mercado de trabalho da Alemanha, Garz (2013) também constatou inferioridade dos salários no setor secundário em relação ao primário; a concentração do sexo masculino, porém, estava presente no setor secundário.

Para a teoria do capital humano, o salário é equivalente à educação e à experiência do trabalhador (WILLINS, 1986). Dessa maneira, em determinada empresa/setor, a diferença salarial pode ser justificada, em partes, pela educação e pelo nível de qualificação profissional. Desse modo, esta parte da pesquisa busca investigar a escolaridade e o tempo de empresa, sendo este último fator caracterizado pela experiência do emprego atual. Posteriormente, será avaliado se os dois fatores influenciam na diferença salarial entre os segmentos e gêneros.

$\mathrm{Na}$ Tabela 4, a escolaridade média dos homens é representada por $\bar{E} m$, das mulheres por $\bar{E} f$, e o desvio-padrão por $d p$. De acordo com a literatura (CALABI; ZAGHEN, 1976; LIMA, 1980; REICH; GORDON; EDWARDS, 1973; SILVA, 2006; SOUZA, 1978), a TSMT afirma que o setor primário necessita de mão de obra qualificada e, consequentemente, mais especializada ou com maior nivel de escolaridade.

Tabela 4: Escolaridade por setor e gênero (grau de instrução)

\begin{tabular}{lcccccccc}
\hline \multirow{2}{*}{ Setor } & \multicolumn{4}{c}{2006} & \multicolumn{5}{c}{2015} \\
\cline { 2 - 9 } & \multicolumn{2}{c}{ Masculino } & \multicolumn{2}{c}{ Feminino } & \multicolumn{2}{c}{ Masculino } & \multicolumn{2}{c}{ Feminino } \\
\cline { 2 - 9 } & $\bar{E} m$ & $d p$ & & $d p$ & $\bar{E} m$ & $d p$ & $\bar{E} f$ & $d p$ \\
\hline Tradicional & 5,41 & 1,71 & 5,60 & 1,67 & 6,08 & 1,65 & 6,22 & 1,62 \\
Moderno & 6,23 & 1,61 & 6,65 & 1,55 & 6,65 & 1,47 & 6,89 & 1,49 \\
\hline
\end{tabular}

Fonte: Elaboração própria com base nos dados do MTE (BRASIL, 2017).

Em relação à mão de obra especializada, segundo o Instituto Nacional de Estudos e Pesquisas Educacionais Anísio Teixeira (Inep), a parcela de estudantes da educação profissional, principalmente a integrada e a concomitante ao ensino médio, aumentou de 2,3\% para $8 \%$ entre 2014 e 2018. Além disso, cerca de $78 \%$ dos alunos têm menos de 30 anos de idade. Mas cabe destacar que, com exceção dos alunos com mais de 60 anos, 
as matrículas das demais faixas etárias são predominantemente do sexo feminino na educação profissional (INEP, 2019).

Quanto ao nível de escolaridade, a Tabela 5 aborda a média educacional para os trabalhadores no segmento moderno e no tradicional. Pode-se observar que a TSMT condiz com a realidade, dado que os empregados mais escolarizados se encontram no segmento moderno nos anos de 2006 e 2015. Entretanto, ela diverge da teoria do capital humano, em que a remuneração é determinada pela educação. Como se pode perceber, as pessoas do sexo feminino têm maior escolaridade do que as do sexo masculino; porém, a remuneração das mulheres na IT, em ambos os segmentos, é inferior à dos homens. Para Magnusson (2013), essa penalização da mão de obra feminina é fruto da desvalorização do trabalho das mulheres ou, simplesmente, pode ser considerada como discriminação desse sexo.

Tabela 5: Nivel de escolaridade por segmento

\begin{tabular}{|c|c|c|c|c|c|c|c|c|}
\hline \multirow{3}{*}{ Escolaridade } & \multicolumn{4}{|c|}{2006} & \multicolumn{4}{|c|}{2015} \\
\hline & \multicolumn{2}{|c|}{ Tradicional } & \multicolumn{2}{|c|}{ Moderno } & \multicolumn{2}{|c|}{ Tradicional } & \multicolumn{2}{|c|}{ Moderno } \\
\hline & $E m$ & $E f$ & $E m$ & $E f$ & $E m$ & $E f$ & $E m$ & $E f$ \\
\hline Analfabeto & $3,1 \%$ & $2,7 \%$ & $1,0 \%$ & $0,8 \%$ & $2,1 \%$ & $1,9 \%$ & $0,8 \%$ & $0,6 \%$ \\
\hline $\begin{array}{l}5^{\circ} \text { ano completo do } \\
\text { ensino fundamental }\end{array}$ & $43,9 \%$ & $39,1 \%$ & $25,8 \%$ & $17,8 \%$ & $31,2 \%$ & $28,4 \%$ & $17,7 \%$ & $14,7 \%$ \\
\hline $\begin{array}{l}\text { Ensino fundamental } \\
\text { completo }\end{array}$ & $30,2 \%$ & $31,5 \%$ & $29,2 \%$ & $27,0 \%$ & $25,2 \%$ & $24,1 \%$ & $21,3 \%$ & $20,4 \%$ \\
\hline $\begin{array}{l}\text { Ensino médio } \\
\text { completo }\end{array}$ & $21,3 \%$ & $24,8 \%$ & $38,8 \%$ & $44,8 \%$ & $37,9 \%$ & $41,0 \%$ & $52,2 \%$ & $51,8 \%$ \\
\hline $\begin{array}{l}\text { Ensino superior } \\
\text { completo }\end{array}$ & $1,5 \%$ & $1,9 \%$ & $5,2 \%$ & $9,6 \%$ & $3,6 \%$ & $4,6 \%$ & $8,0 \%$ & $12,5 \%$ \\
\hline
\end{tabular}

Fonte: Elaboração própria com base nos dados do MTE (BRASIL, 2017)

No que se refere aos analfabetos, conforme a Tabela 5, não existe diferença entre os sexos, e no ensino fundamental o número de homens é mais expressivo que o de mulheres. Mas, ao analisar o ensino médio e o superior, o cenário se inverte, comprovando que o sexo feminino é mais escolarizado que o masculino. Conforme Melo e Oliveira (2006), no ensino superior, especialmente no campo de pesquisas científicas, as mulheres também são mais escolarizadas que os homens - cerca de 1,4\% contra 1,36\% -, demonstrando que está havendo um empoderamento do sexo feminino na sociedade.

Ao averiguar os segmentos, nota-se que os trabalhadores mais escolarizados se encontram no moderno. Entretanto, conforme descrito anteriormente, na Tabela 2, a proporção de trabalhadores masculinos no segmento 
moderno é maior do que a do sexo feminino, mesmo que as mulheres sejam mais escolarizadas. Cabe destacar ainda que o nivel educacional varia conforme o setor: por exemplo, nas áreas tipicamente masculinas, como é o caso da fabricação de veículos automotores, reboques e carrocerias, os homens são os mais escolarizados. Já no setor de fabricação de produtos farmoquímicos e farmacêuticos, que detém maior participação feminina, as mulheres apresentam maior nivel educacional.

Apesar das exceções, verifica-se que ainda há preferência pelo sexo masculino no mercado de trabalho. De acordo com Moraes (2005), os empregadores preferem pagar maiores salários para os homens, pois o retorno do sexo feminino é menor devido ao período que a mulher demanda de licença maternidade, encarecendo os custos da contratação dessa mão de obra. Fiuza-Moura et al. (2014) chegaram a resultados semelhantes e concluem que a mulher com baixo grau de instrução enfrenta maiores dificuldades para se inserir no mercado de trabalho da IT.

Para finalizar a análise proposta, no que tange ao tempo médio de empresa, Reich, Gordon e Edwards (1973) afirmam que, nos setores que necessitam de mão de obra qualificada, a rotatividade de empregados é menor. Esse efeito, segundo os autores, é devido aos elevados custos com treinamentos, de forma que se torna mais vantajoso para o empregador manter o funcionário mais antigo, resultando em maior benefício para o trabalhador devido à maior estabilidade no emprego.

Nesse sentido, a Tabela 6 dispõe o tempo médio de empresa por sexo. Como se pode observar, a afirmação de Reich, Gordon e Edwards (1973) condiz com os resultados encontrados, segundo os quais os funcionários do segmento moderno apresentam maior tempo médio de empresa, em ambos os anos e gêneros.

Tabela 6: Tempo médio de empresa (em anos)

\begin{tabular}{lccccccccc}
\hline \multirow{2}{*}{ Segmentos } & \multicolumn{4}{c}{2006} & \multicolumn{3}{c}{2015} \\
\cline { 2 - 10 } & \multicolumn{2}{c}{ Masculino } & \multicolumn{2}{c}{ Feminino } & \multicolumn{2}{c}{ Masculino } & \multicolumn{2}{c}{ Feminino } \\
\cline { 2 - 9 } & $\bar{T}$ & $d p$ & $\bar{T}$ & $d p$ & $\bar{T}$ & $d p$ & $\bar{T}$ & $d p$ \\
\hline Tradicional & 4,09 & 2,11 & 3,83 & 1,97 & 4,32 & 2,20 & 4,17 & 2,06 \\
Moderno & 4,42 & 2,21 & 4,21 & 2,06 & 4,66 & 2,26 & 4,59 & 2,00 \\
\hline
\end{tabular}

Fonte: Elaboração própria com base nos dados do MTE (BRASIL, 2017).

Tanto para o sexo masculino quanto para o feminino, o dp é menor que o tempo médio de empresa em ambos os segmentos, demonstrando que a 
estabilidade dos trabalhadores tende a ficar próxima da média, isto é, mantendo um comportamento padronizado. Os dados também permitem visualizar que os homens possuem maior tempo de vínculo dentro da mesma empresa do que as mulheres. Tal resultado pode justificar parte da diferença salarial entre homens e mulheres, dado que quanto maior o tempo de vínculo do empregado com a empresa, maior será sua remuneração. Schultz (1961) considera a experiência como parte do capital humano e por isso defende que a remuneração deve variar conforme o acúmulo educacional, de treinamento e de experiência profissional.

Outro fator que pode contribuir para explicar o menor tempo de vínculo empregatício das mulheres é a combinação entre o trabalho remunerado e o não remunerado. Segundo Bruschini (2006), empregos de menor qualidade, baixos salários e carreiras descontínuas são resultado da limitação do desenvolvimento profissional ocasionada pela articulação entre a produção econômica e a reprodução social da mulher. Na mesma perspectiva, Sousa e Guedes (2016) evidenciaram, para os anos de 2004 a 2014, que a participação e a permanência das mulheres no mercado de trabalho têm forte relação com a conciliação entre o trabalho e a família, pois elas se dedicam mais horas aos cuidados domésticos do que o homem e, no mínimo, seis horas a menos ao trabalho remunerado.

Os resultados apontaram que dentro dos segmentos existem distinções entre homens e mulheres, apesar de o tempo médio de empresa contribuir para explicar parte dessa diferença, uma vez que os homens permanecem nos empregos por mais tempo do que as mulheres. De acordo com Abendroth, Maas e Lippe (2013) e Triventi (2013), as características de emprego, a experiência do empregador e as horas trabalhadas contribuem para esclarecer a diferença entre os gêneros.

Essa disparidade nos segmentos tem reflexos negativos não somente para o mercado de trabalho, mas para a sociedade em geral. Para Wang, Piesse e Ye (2016), um dos fatores que aumenta a desigualdade está relacionado à diferença de renda no mercado de trabalho. Já para Alt e Iversen (2017), a desigualdade gerada pela redução do apoio na redistribuição de renda apresenta maior vínculo com o aumento da segmentação do mercado de trabalho.

Segundo Ometto (1997), a distribuição dos trabalhadores não ocorre de forma igualitária, pois as mulheres se deparam com barreiras relativas a cargos e remunerações. Conforme Guedes e Araújo (2011), a diferença salarial se faz presente principalmente nos cargos com maior nível de 
escolaridade, como também a segmentação nos cargos de menor prestígio, fazendo com que a igualdade não prevaleça na realidade brasileira.

Por esse motivo, Peetz (2015) e Rubery e Piasna (2016) defendem a necessidade de políticas de equidade entre gêneros e de apoio de organizações sindicais para minimizar essa situação, proporcionando melhores condições de trabalho e estabilidade na renda, a fim de garantir uma carreira igualitária entre os gêneros.

De acordo com Camargos, Riani e Marinho (2014), no Brasil, ainda existem vestígios de um modelo tradicional em que a mulher se sobrecarrega com responsabilidades do cuidado da casa e com o trabalho. Para as autoras, uma possibilidade para reverter tal desigualdade é estabelecer elementos que conciliem trabalho produtivo e reprodutivo. De acordo com Triventi (2013), os países nórdicos diminuíram a desigualdade entre gêneros com políticas voltadas para a familia.

Dessa maneira, percebe-se que a IT do estado do Paraná necessita de mudança de cultura por parte dos empregadores, mediante utilização de políticas contra a desigualdade de gêneros, a fim de minimizar as barreiras para o ingresso das mulheres no mercado de trabalho, possibilitando que elas adquiram maior espaço dentro dos seus segmentos.

\section{Considerações finais}

Esta pesquisa teve como objetivo compreender o mercado de trabalho paranaense, por meio da TSMT, a fim de averiguar, para os anos de 2006 e 2015, se existe desigualdade entre homens e mulheres na participação, remuneração, escolaridade e tempo de vínculo empregatício, para o segmento tradicional e o moderno da IT, cuja diferença é a intensidade tecnológica.

Mediante análise dos dados, constatou-se que a participação das mulheres aumentou no periodo analisado, apesar de continuar inferior à participação masculina. Aos poucos a mulher está expandindo sua área de atuação em setores que, anteriormente, eram voltados somente para o sexo masculino.

Contudo, evidenciou-se que ambos os segmentos concentram trabalhadores do sexo masculino e que estes têm melhor remuneração que as mulheres - principalmente no segmento moderno, o qual apresentou, em 2015, os maiores salários e cerca de $75 \%$ de participação do sexo masculino. Apesar de esse segmento demandar mão de obra qualificada, as mulheres, que possuem maior escolaridade, ainda são minoria, não obstante isso ocorra, 
em alguns casos específicos, em áreas tipicamente femininas. Porém, em termos gerais, a pesquisa revela a existência de discriminação da mulher no mercado de trabalho e problematiza a teoria do capital humano, a qual defende que a remuneração acompanha a escolaridade - embora, em alguns casos, as áreas escolares em que as mulheres são maioria sejam diferentes daquelas ocupadas predominantemente pelos homens no ensino superior.

Outro fator analisado foi o tempo médio de vínculo empregatício. Os resultados demonstraram que o segmento moderno oferece maior estabilidade aos empregados, principalmente aos homens que indicaram maior período de permanência na empresa que as mulheres. $\bigcirc$ tempo médio de vínculo pode ser um dos fatores que ajudam a explicar a diferença dos rendimentos entre os sexos; porém, também pode estar relacionado à dupla jornada de trabalho feminino.

Esses fatos indicam uma possivel discriminação contra o sexo feminino e uma provável barreira de entrada no mercado de trabalho para as mulheres menos escolarizadas. Para minimizar tal situação, políticas familiares podem ser desenvolvidas de forma a auxiliar tanto no trabalho produtivo como reprodutivo. Na sociedade de hoje, este é um tema que já deveria estar resolvido, justamente pelo fato de a sociedade estar incentivando o respeito e a inclusão social; no entanto, não foi isso que se evidenciou neste estudo. Portanto, indicam-se futuras pesquisas sobre a discriminação contra a mulher no mercado de trabalho, com outros métodos de análise, em períodos diferentes e até mesmo em outros setores, a fim de contribuir para minimizar tal situação.

\section{Referências}

ABENDROTH, A. K.; MAAS, I.; LIPPE, T. V. D. Human capital and the gender gap in authority in European countries. European Sociological Review, Oxford, v. 29, n. 2, p. 261-273, 2013.

ALT, J.; IVERSEN, T. Inequality, labor market segmentation, and preferences for redistribution. American Journal of Political Science, Hoboken, v. 61, n. 1, p. 21-36, 2017.

ARAÚJO, M. F. Diferença e igualdade nas relações de gênero: revisitando o debate. Psicologia Clínica, Rio de Janeiro, v. 17, n. 2, p. 41-52, 2005. 
BAYLÃO, A. L. S.; SCHETTINO, E. M. O. A inserção da mulher no mercado de trabalho brasileiro. In: SIMPÓSIO DE EXCELÊNCIA EM GESTÃO E TECNOLOGIA, 11., 2014, Resende. Anais [...]. Resende: Faculdades Dom Bosco, 2014. p. 1-12. Disponivel em: https://bit.ly/3dJZlgb. Acesso em: 8 set. 2017.

BLUESTONE, B. The tripartite economy: labor markets and the working poor. Poverty and Human Resource Abstracts, Ann Arbor, v. 5, n. 4, p. 15-35, 1970.

BRASIL. Secretaria Especial de Políticas para as Mulheres. Plano Nacional de Políticas para as Mulheres. Brasilia, DF: Secretaria Especial de Políticas para as Mulheres, 2005.

BRASIL. Ministério do Trabalho e Emprego. RAIS: Relação Anual de Informações Sociais. Brasilia, DF: MTE, 2017. Disponivel em: https://bit.ly/2NIBjYO. Acesso em: 1 ago. 2017.

BRUSCHINI, C. Trabalho doméstico: inatividade econômica ou trabalho nãoremunerado? Revista Brasileira de Estudos de População, São Paulo, v. 23, n. 2, p. 331-353, 2006.

CALABI, A. S.; ZAGHEN, P. E. M. Segmentação do mercado de trabalho, mobilidade e rotatividade: revisão teórica e evidências empíricas preliminares. São Paulo: FIPE, 1976. Mimeografado.

CAMARGOS, M. C. S.; RIANI, J. L. R.; MARINHO, K. R. L. Mercado de trabalho e gênero: uma análise das desigualdades em Minas Gerais. Pretexto, Belo Horizonte, v. 15, p. 41-47, 2014.

CUGINI, S. C. B.; MAIA, K.; LOPES, R. L.; DEVIDÉ JUNIOR, A.; SOUZA, S. C. I. A força de trabalho feminina no mercado de trabalho brasileiro: discriminação salarial por gênero, em 2002 e 2011. In: ENCONTRO DE ECONOMIA PARANAENSE, 11., 2014, Apucarana. Anais [...]. Apucarana: Unespar, 2014. p. 1-19. Disponivel em: https://bit.ly/31qBwqW. Acesso em: 13 set. 2017.

DOERINGER, P. B.; PIORE, M. J. Internal labor markets and manpower analysis. Lexington, MA: D. C. Heath, 1971.

FIUZA-MOURA, F. K.; NAKATANI-MACEDO, C. D.; SOUZA, S. C. I.; MAIA, K._Capital humano e segmentação no mercado de trabalho: uma análise 
da indústria paranaense, por níveis de intensidade tecnológica. In: ENCONTRO DE ECONOMIA PARANAENSE, 11., 2014, Apucarana. Anais [...]. Apucarana: Unespar, 2014. p. 1-20.

GARZ, M. Labour market segmentation: standard and non-standard employment in Germany. German Economic Review, Berlin, v. 14, n. 3, p. 349-371, 2013.

GUEDES, M. C.; ARAÚJO, C. Desigualdades de gênero, família e trabalho: mudanças e permanências no cenário brasileiro. Revista Gênero, Niterói, v. 12, n. 1, p. 61-79, 2011.

IBGE. Comissão Nacional de Classificação. Pesquisa CNAE 2.0: hierarquia. Rio de Janeiro: IBGE, 2017. Disponível em: https://bit.ly/2VtRHjr. Acesso em: 1 ago. 2017.

INEP. Resumo técnico: Censo da Educação Básica 2018. Brasilia, DF: Inep, 2019.

ITABORAÍ, N. R. Trabalho feminino e mudanças nas famílias no Brasil (19762012): uma perspectiva de classe e gênero. Revista Gênero, Niterói, v. 16, n. 2, p. 173-199, 2016.

LIMA, R. Mercado de trabalho: o capital humano e a teoria da segmentação. Pesquisa e Planejamento Econômico, Rio de Janeiro, v. 10, n. 1, p. 217-272, 1980.

MACEDO, R. B. M. Os salários na teoria econômica. Rio de Janeiro: Ipea: Inpes, 1982. (Série Programa Nacional de Pesquisa Econômica, 2).

MAGNUSSON, C. More women, lower pay? Occupational sex composition, wages and wage growth. Acta Sociologica, Thousand Oaks, v. 56, n. 3, p. 227-245, 2013.

MELO, H. P.; OLIVEIRA, A. B. A produção científica brasileira no feminino. Cadernos Pagu, Campinas, n. 27, p. 301-332, 2006.

MORAES, S. M. A. Discriminação salarial por gênero nos segmentos industriais do Brasil: uma análise para os anos de 1993, 1998 e 2003. 2005. 106 f. Dissertação (Mestrado em Desenvolvimento Econômico) Universidade Federal do Paraná, Curitiba, 2005. 
OMETTO, A. M. H. Participação da mulher no mercado de trabalho: segregação e discriminação em Pernambuco e São Paulo. 1997. Tese (Doutorado em Economia Aplicada) - Universidade de São Paulo, Piracicaba, 1997.

PAULA, L. F.; PIRES, M. Crise e perspectivas para a economia brasileira. Estudos Avançados, São Paulo, v. 31, n. 89, p. 125-144, 2017.

PEETZ, D. Regulation distance, labour segmentation and gender gaps. Cambridge Journal of Economics, Oxford, v. 39, n. 2, p. 345-362, 2015.

REICH, M.; GORDON, D. M.; EDWARDS, R. C. A theory of labor market segmentation. The American Economic Review, Pittsburgh, v. 63, n. 2, p. 359-365, 1973.

RUBERY, J.; PIASNA, A. Labour market segmentation and the EU reform agenda: developing alternatives to the mainstream. ETUI Working Papers. Brussels: ETUI, n. 2016.10, 2016. 30 p.

SCHULTZ, T. W. Investment in human capital. The American Economic Review, Pittsburgh, v. 51, n. 1, p. 1-17, 1961. Disponivel em: https://bit.ly/2ZnG12W. Acesso em: 10 nov. 2019.

SILVA, E. M. M. As disparidades salariais por gênero no mercado de trabalho brasileiro: 1995, 2001, 2006 e 2012. 2014. 36 f. Monografia (Graduação em Ciências Econômicas) - Universidade Federal do Paraná, Curitiba, 2014.

SILVA, I. Teorias do emprego segundo o enfoque do capital humano, da segmentação e dos mercados internos. Revista da Fapese, Aracaju, v. 2, n. 2, p. 129-140, 2006.

SOUSA, L. P; GUEDES, D. R. A desigual divisão sexual do trabalho: um olhar sobre a última década. Estudos Avançados, São Paulo, v. 30, n. 87, p. 123-139, 2016.

SOUZA, M. C. C. Mercados de trabalho: abordagens duais. Revista de Administração de Empresas, Rio de Janeiro, v. 18, n. 1, p. 59-69, 1978.

TRIVENTI, M. The gender wage gap and its institutional context: a comparative analysis of European graduates. Work, Employment and Society, Thousand Oaks, v. 27, n. 4, p. 563-580, 2013. 
VIETORISZ, T.; HARRISON, B. Labor market segmentation: positive feedback and divergent development. American Economic Review, Pittsburgh, v. 63, n. 2, p. 366-376, 1973.

WANG, X.; PIESSE, J.; YE, Z. Labour markets in China: a study of the structure and evolution of wages. Frontiers of Economics in China, Shanghai, v. 11, n. 2, p. 265-301, 2016.

WILLINS, R. J. Wage determinants: a survey and reinterpretation of human capital earnings functions. In: ASHENFELTER, O.; LAYARD, R. (ed.). Handbook of labor economics. Amsterdam: North-Holland, 1986.

Recebido em fevereiro de 2019.

Aprovado em março de 2020. 